\title{
Tissue Plasminogen Activator Mediates Microglial Activation via Its Finger Domain through Annexin II
}

\author{
Chia-Jen Siao and Stella E. Tsirka \\ Department of Pharmacological Sciences and Program in Molecular and Cellular Pharmacology, University Medical \\ Center at Stony Brook, Stony Brook, New York 11794
}

\begin{abstract}
Microglia are the immunocompetent cells of the CNS, and their activation is thought to play an important neurotoxic role in many diseases modeled by glutamate-induced excitotoxicity. One molecule whose expression is upregulated after excitotoxic injury is tissue plasminogen activator (tPA), a serine protease with dual roles in the CNS. The catalytic activity of tPA, which converts plasminogen into plasmin, leads to neuronal death during excitotoxicity. Via a nonproteolytic mechanism, tPA also mediates microglial activation. We show here in culture studies that stimulated wild-type neurons and microglia can release the tPA that elicits the activation, and that tPA acts in
\end{abstract}

combination with other factors. We also show that the finger domain of tPA is necessary to trigger the activation and identify annexin II as its probable binding partner-receptor. Together, these findings suggest that tPA released by either neurons or microglia can act as a neural cytokine, signaling through annexin II to activate microglia in settings of disease and injury. Developing methods to inhibit the interaction of tPA with annexin II would offer a new and selective approach to interfere with microglial activation for therapeutic purposes.

Key words: nonproteolytic; cell signaling; cytokine; receptor; domain deletions; F4/80 glycoprotein
Microglia, derived from the monocyte/macrophage lineage, are considered the immune cells of the brain (Kreutzberg, 1996). After injury, they become activated and acquire a stereotypical phenotype (Streit et al., 1999) that includes proliferation and increased expression of specific markers [e.g., nitric oxide (NO), interleukin-1 (IL-1), tumor necrosis factor (TNF)- $\alpha$, proteases, and the surface glycoprotein F4/80], changes in morphology (from ramified to amoeboid), migration toward injured cells, and acquisition of antigen presentation and phagocytosis properties.

Activated microglia accumulate in many CNS diseases. They cluster around amyloid plaques in Alzheimer's disease (Giulian, 1999), are found in the brains of animals with scrapie (RusselakisCarneiro et al., 1999), and have been implicated in the progression of multiple sclerosis and human immunodeficiency virus dementia (Gonzalez-Scarano and Baltuch, 1999). Ischemic events induce vigorous and prolonged microglial activation (for review, see Stoll et al., 1998), which increases the ensuing neurotoxicity by exacerbating the initial insult into the surrounding region (Yenari and Giffard, 2001).

Microglial activation in part regulates the neuronal death pathway known as excitotoxicity (Rogove and Tsirka, 1998). Excitotoxicity, which is observed after overstimulation of neurons with excitatory neurotransmitters, is a component in several neuropathologies (Dickson et al., 1993; DiPatre and Gelman, 1997) and is modeled in animals by injection of glutamate analogs such as kainate (KA) (Olney, 1986). Pharmacological delay of microglial

Received Sept. 19, 2001; revised Jan. 24, 2002; accepted Jan. 29, 2002.

This work was supported by a Neurotoxin Research Program grant from the United States Army Medical Research to S.E.T. We thank Drs. Michael Frohman, Lincoln Stein, and Chuck O'Neal for critically reviewing this manuscript. We are also grateful to Genentech Inc. for providing the deletion domain mutant tPA proteins.

Correspondence should be addressed to Dr. Stella E. Tsirka, Department of Pharmacological Sciences, BST-7, Room 183, University Medical Center at Stony Brook, Stony Brook, NY 11794-8651. E-mail: stella@pharm.sunysb.edu.

Copyright (C) 2002 Society for Neuroscience $0270-6474 / 02 / 223352-07 \$ 15.00 / 0$ activation protects neurons from KA-induced excitotoxicity (Rogove and Tsirka, 1998).

Tissue plasminogen activator (tPA) is a serine protease; its activation of plasmin is critical for the progression of excitotoxicity (Tsirka et al., 1995, 1997). Plasmin degrades laminin (Chen and Strickland, 1997) and possibly other extracellular matrix (ECM) molecules, and the loss of this substratum promotes neuronal death.

Microglia from $\mathrm{tPA}^{-/-}$mice show attenuated activation after KA injection. Infusion of either catalytically active or catalytically inactive tPA into these mice before KA injection restores microglial activation (Rogove et al., 1999). These data indicate that contrary to its proteolytic role in neurotoxicity, tPA activates microglia via a nonproteolytic mechanism. In addition to its catalytic domain, tPA also contains a fibronectin type-3 finger domain (F), an epidermal growth factor-like (GF) domain, and two kringle domains (K1 and K2), which are thought to mediate protein-protein interactions. The finger domain binds fibrin (van Zonneveld et al., 1986) and annexin II (Hajjar et al., 1994). The GF domain, well characterized in other proteins, is necessary for urokinase plasminogen activator, the other mammalian plasminogen activator, to bind to and activate its receptor (Rabbani et al., 1992). The kringle domains bind fibrin (van Zonneveld et al., 1986), and the second kringle also binds lysine (Gething et al., 1988). Moreover, in addition to mediating the proteolytic function of tPA, the catalytic domain binds to vascular smooth muscle cells (Werner et al., 1999). The catalytic domain also mediates binding to inhibitors such as the plasminogen activator inhibitors (van Zonneveld et al., 1986).

In this report, we use deletion analysis of tPA to define the mechanism through which tPA activates microglia. We find that tPA released from neurons or microglia activates microglia via its finger domain, which most likely interacts with annexin II, a cell-surface receptor, to initiate an intracellular signaling cascade. 


\section{MATERIALS AND METHODS}

Recombinant human tPA and mutants lacking the finger $(\Delta \mathrm{F})$, epidermal growth factor $(\Delta \mathrm{GF})$, kringle $1(\Delta \mathrm{K} 1)$, or kringle $2(\Delta \mathrm{K} 2)$ domains were a generous gift from Genentech Inc. (San Francisco, CA). The tPA proteins were used at a concentration of $500 \mathrm{ng} / \mathrm{ml}$ unless otherwise noted. Bacterial lipopolysaccharide (LPS; strain O55:B5; Sigma, St. Louis, MO) was used at $100 \mathrm{ng} / \mathrm{ml}$.

\section{Animal studies and cell culture}

C57BL/6 (wild-type) and tPA ${ }^{-1-}$ (Carmeliet et al., 1994) mice were obtained from The Jackson Laboratory (Bar Harbor, ME) and maintained in the Stony Brook Department of Laboratory Animal Research with access to food and water ad libitum. The tPA ${ }^{-1-}$ animals were further backcrossed to C57BL/6 mice for nine generations, and progeny of those mice were used for the experiments. All procedures followed guidelines set by the National Institutes of Health and were approved by Stony Brook University. Cultured cells were incubated at $37^{\circ} \mathrm{C}$ with $5 \%$ $\mathrm{CO}_{2}$. All tissue culture media and additives were from Invitrogen (San Diego, CA) except as noted.

Neuronal cultures were made as described previously (Rogove and Tsirka, 1998). Briefly, the hippocampi from embryonic day 17.5 mouse embryos were dissected and gently trypsinized (0.25\% trypsin in HBSS) at $37^{\circ} \mathrm{C}$ for $15 \mathrm{~min}$ and then triturated to form single-cell suspensions. The cells were plated onto poly-L-lysine precoated coverslips at a density of 100,000 cells $/ \mathrm{cm}^{2}$ in neurobasal medium with B27 supplements, $25 \mu \mathrm{M}$ glutamate, $0.5 \mathrm{~mm}$ L-glutamine, and $10 \mathrm{gm} / 1$ gentamycin sulfate. The medium was changed $4 \mathrm{hr}$ after the initial plating, and the glutamate was removed after $4 \mathrm{~d}$ in culture. Neurons were used after at least $7 \mathrm{~d}$ in vitro. Neuronal conditioned medium (CM) was obtained from cells stimulated with $25 \mu \mathrm{M}$ L-glutamate for $4 \mathrm{hr}$.

Microglial cultures were made from mixed cortical cultures as described previously (Rogove and Tsirka, 1998) except that single cells, obtained by passage through a $70 \mu \mathrm{m}$ nylon mesh, were plated into poly-L-lysine-precoated $75 \mathrm{~cm}^{2}$ tissue culture flasks at a density of two brains per flask. The mixed cortical cultures were used to isolate microglia after $14 \mathrm{~d}$ in vitro, when the cells were selectively released from the flasks by incubation with $15 \mathrm{~mm}$ lidocaine for $7 \mathrm{~min}$ at room temperature, followed by gentle shaking for $3 \mathrm{~min}$ by hand. After low-speed centrifugation, the cell pellet was resuspended in complete medium and plated onto poly-L-lysine-precoated 48 well plates $(0.25 \mathrm{ml}$ culture volume per well). The microglia were used at least $2 \mathrm{~d}$ after subculture, by which time their morphology resembled that of resting microglia. To obtain microglial CM with the LPS removed, microglia were primed with $100 \mathrm{ng} / \mathrm{nl}$ LPS overnight, and then the medium was collected, passed over a polymyxin B-agarose column as directed by the manufacturer (Sigma), and sterilized through a $0.22 \mu \mathrm{m}$ syringe filter. Endotoxin removal was assayed using the Pyrogent Plus kit (BioWhittaker, Walkersville, MD). Ten endotoxin units (E.U.) of residual LPS were detected, compared with the 25 E.U. originally added. Blocking molecules (see below), when used, were added to the cell cultures $1 \mathrm{hr}$ before addition of tPA. After the addition of tPA, the cultures were continued for 1-24 hr before adding LPS for a final overnight culture period. We found no difference in microglial activation regardless of whether the tPA was added for short $(1 \mathrm{hr})$ or long $(24 \mathrm{hr})$ periods before the addition of LPS. For some experiments, tPA at a $500 \mathrm{ng} / \mathrm{ml}$ final concentration was added to the tPA $^{-1-} \mathrm{CM}$, or $\alpha$-tPA antibody (clone N-14, $600 \mathrm{ng} / \mathrm{ml}$; Santa Cruz Biotechnology, Santa Cruz, CA) was added to the wild-type CM, before the addition of these CM to the microglial cultures (Fig. 1).

\section{Microglial activation}

Immunocytochemistry. Microglia were fixed on their coverslips with $4 \%$ paraformaldehyde-20\% sucrose and then permeabilized using $0.1 \%$ Triton X-100. After blocking with goat serum (10\% in PBS), the rat anti-F4/80 antibody (Serotec, Indianapolis, IN) was used at a 1:200 dilution, followed by incubation with biotinylated anti-rat $\operatorname{IgG}(1: 1000$; Vector Laboratories, Burlingame, CA). The signal was amplified using the Vector Laboratories avidin-biotin complex Elite kit (avidin coupled with horseradish peroxidase) and detected using diaminobenzidineperoxide (Sigma), after which the coverslips were successively dehydrated in ethanol, delipidated in xylenes, and mounted using Permount (Fisher, Houston, TX).

Quantitative Western blot. Cultured microglia were lysed in $0.25 \%$ Triton X-100 in PBS. After centrifuging to remove cell debris, the total protein concentration was measured using the Bio-Rad (Hercules, CA)
Bradford detergent-compatible (Dc) assay. Equal amounts $(20 \mu \mathrm{g})$ of protein from each sample were separated on $10 \%$ SDS-PAGE, transferred onto polyvinylidene difluoride membrane, blocked with 5\% nonfat dry milk in PBS/0.5\% Tween 20 (PBS-T), and incubated with F4/80 antibody (1:200 dilution) overnight in milk/PBS-T. Biotinylated secondary anti-rat antibodies were used (1:500 dilution) and were detected using FITC-labeled ExtrAvidin (1:200; Sigma). Fluorescence was detected by a FluorImager (Molecular Devices, Menlo Park, CA) and quantified using the ImageQuant (Amersham, Sunnyvale, CA) software.

Nitrite detection. The production of nitric oxide from activated cells was measured in the form of nitrites according to the method of Si et al. (1997). CM from treated microglia was collected and refrigerated before detection, after which $20 \mu \mathrm{l}$ of $0.05 \mathrm{mg} / \mathrm{ml}$ diaminonaphthalene (Molecular Probes, Eugene, OR) in $0.28 \mathrm{~N} \mathrm{HCl}$ was added to $100 \mu \mathrm{l}$ of CM per well in a 96 well black plate (Nunc, Naperville, IL), which was then incubated at room temperature for $10 \mathrm{~min}$. The reactions were terminated by the addition of $100 \mu \mathrm{l}$ of $0.28 \mathrm{~N} \mathrm{NaOH}$ followed by incubation for $10 \mathrm{~min}$. The generation of nitrites was measured using a microplate fluorescence reader (Titertek, Huntsville, AL) with $365 \mathrm{~nm}$ excitation and $450 \mathrm{~nm}$ emission filters.

\section{Annexin II analysis}

Reverse transcription-PCR. Total RNA was isolated from cultured microglia and neurons using Trizol (Invitrogen) according to the manufacturer's directions. Reverse transcription (RT) was performed using poly-T primers and Moloney murine leukemia virus (Invitrogen) according to the manufacturer's directions. PCR for annexin II was performed using the following primers: 5'-ATGTCTACTGTCCACGAAATC-3' (forward) and 5'-CAGGTAGAGCCACTTCTGGG-3' (reverse). For amyloid precursor protein (APP), the primers used were $5^{\prime}$-CGATGGGGGATGCTTCTTGTG-3' (forward) and 5'-GCTATCATGGCATAAGCAATG-3' (reverse).

Western blot analysis. Total protein from cultured neurons or microglia was lysed in $0.25 \%$ Triton X-100 and clarified by centrifugation. Total protein $(5 \mu \mathrm{g})$ from the supernatant, quantified using the Bio-Rad Bradford Dc assay, was separated on a $10 \%$ SDS-polyacrylamide gel and transferred to a polyvinylidene difluoride membrane. $\alpha$-Annexin II was detected using a monoclonal antibody (1:1000 final dilution; Transduction Laboratories, Lexington, KY). To verify cell-specific blotting, $\alpha$-microtubule-associated protein-2 (a neuronal marker; 1:700; Sigma) antisera and F4/80 (a macrophage/microglial marker) were used. To show equal loading of proteins, an $\alpha$-actin antibody (1:250; Sigma; a generous gift from Dr. M. Berrios, State University of New York at Stony Brook, Stony Brook, NY) was used.

Antibody blocking assays. Primary $\mathrm{tPA}^{-1-}$ microglia were plated as above. Antibodies were added in the following amounts (in $\mu \mathrm{g}$ ): 1 $\alpha$-annexin II, 1 mouse IgG1 (Sigma), $5 \alpha$-low-density lipoprotein receptor-related protein (LRP) (rabbit anti-human antiserum; a generous gift from Dr. G. Bu, Washington University, St. Louis, MO). After incubation for $1 \mathrm{hr}$, tPA was added for another hour, and finally LPS was added and cells were incubated overnight before analysis.

\section{RESULTS}

\section{Both neurons and microglia can activate microglia in a paracrine and tPA-dependent manner}

Purified wild-type microglia stimulated with LPS become activated, whereas $\mathrm{tPA}^{-1-}$ microglia do not unless exogenous tPA is added to the culture (Rogove et al., 1999). However, addition of exogenous tPA in the absence of LPS does not result in activation. These findings suggest that LPS priming stimulates several events required for activation, one of which could be the release of tPA, which would then further stimulate the microglia in an autocrine-paracrine manner. Alternatively, we have proposed that neuronal release of tPA could also activate the primed microglia at this step. To address these hypotheses, we developed a system to assess whether defective $\mathrm{tPA}^{-/-}$microglial activation can be rescued using CM from glutamate-stimulated purified neurons and LPS-primed microglia.

In the absence of manipulation, the cultured $\mathrm{tPA}^{-/-}$microglia used for the experiments displayed primarily a resting phenotype, which is characterized by small cell bodies with long, thin pro- 


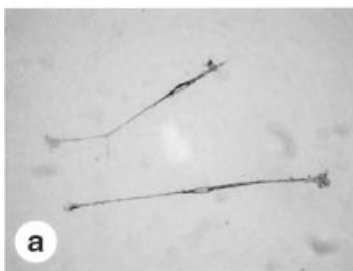

not treated

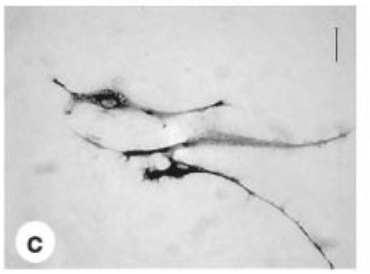

tPA-/- nCM

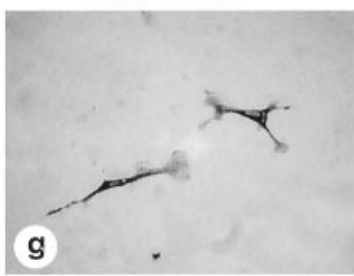

tPA-/- mgCM

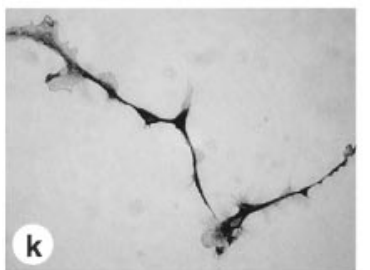

wt nCM

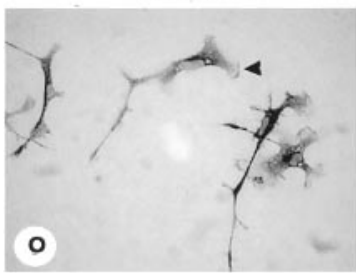

wt mgCM

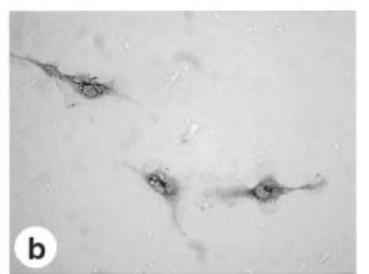

LPS

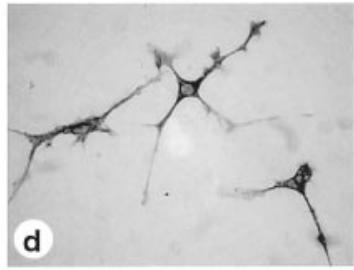

Glu-stimulated tPA-/- nCM
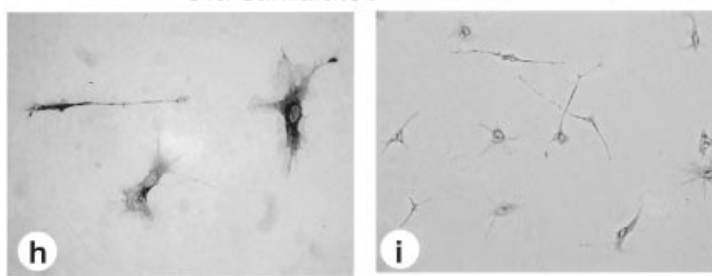

LPS-stimulated tPA-/- mgCM
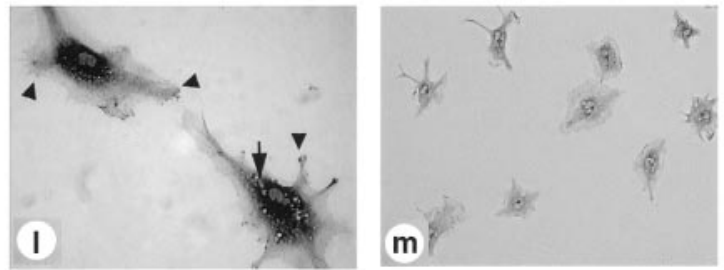

Glu-stimulated wt nCM
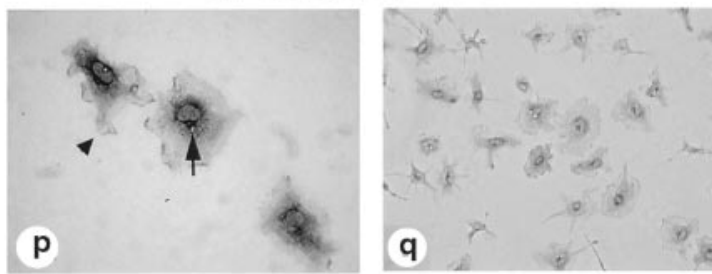

LPS-stimulated wt mgCM

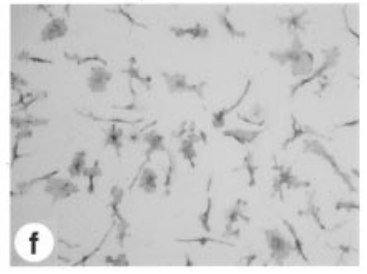

$+500 \mathrm{ng} / \mathrm{ml} \mathrm{tPA}$

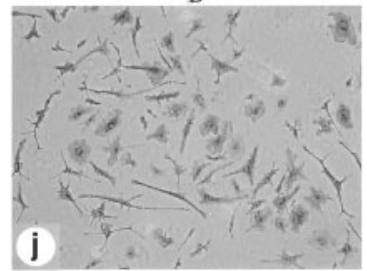

$+500 \mathrm{ng} / \mathrm{ml}$ tPA

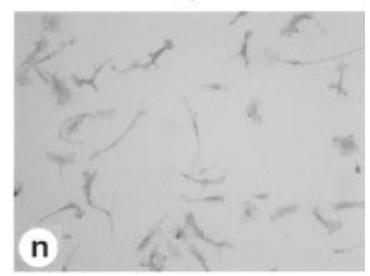

$+\alpha-\mathrm{tPA}$

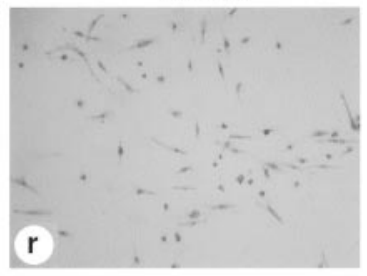

$+\alpha-\mathrm{tPA}$

Figure 1. $\mathrm{tPA}^{-1-}$ microglia in culture respond to signals released from injured neurons and microglia by becoming activated and changing morphology. Cells were treated as described in Results, and the expression of F4/80 was examined. $a$, Control, untreated tPA ${ }^{-1-}$ microglia (400× magnification). $b$, $100 \mathrm{ng} / \mathrm{ml}$ LPS $\left(400 \times\right.$ magnification). $c$, CM prepared from quiescent tPA ${ }^{-/}$neurons $(400 \times$ magnification). $d$, CM prepared from glutamate (Glu)-stimulated $\mathrm{tPA}^{-1-}$ neurons $\left(400 \times\right.$ magnification). $e$, Same as $d\left(100 \times\right.$ magnification). $f, \mathrm{CM}$ prepared from glutamate-stimulated tPA ${ }^{-/-}$neurons additionally containing tPA at $500 \mathrm{ng} / \mathrm{ml}\left(100 \times\right.$ magnification). $g, \mathrm{CM}$ prepared from quiescent $\mathrm{tPA}^{-1-}$ microglia (400× magnification). $h$, CM prepared from LPS-stimulated $\mathrm{tPA}^{-1-}$ microglia. The LPS was partially removed using a polymyxin B column before addition of the CM to the responding tPA $^{-1-}$ microglia (400× magnification). $i$, Same as $h\left(100 \times\right.$ magnification). $j$, CM prepared from LPS-stimulated tPA ${ }^{-1-}$ microglia additionally containing tPA at $500 \mathrm{ng} / \mathrm{ml}$. The LPS was partially removed using a polymyxin B column before addition of the $\mathrm{CM}$ to the responding tPA ${ }^{-1-}$ microglia (100× magnification). $k, C$ M prepared from quiescent wild-type neurons $(400 \times$ magnification). $l$, CM prepared from glutamate-stimulated wild-type neurons (400× magnification). $m$, Same as $l(100 \times$ magnification). $n, \mathrm{CM}$ prepared from $\alpha$-tPA antibody of glutamate-stimulated wild-type neurons (100× magnification). $o, \mathrm{CM}$ prepared from quiescent wild-type microglia $(400 \times$ magnification). $p$, CM prepared from LPS-stimulated wild-type microglia. The LPS was partially removed using a polymyxin B column before addition of the CM to the responding tPA ${ }^{-/-}$microglia $(400 \times$ magnification). $q$, Same as $p(100 \times$ magnification). $r$, CM prepared from $\alpha$-tPA antibody of LPS-stimulated wild-type microglia. The LPS was partially removed using a polymyxin B column before addition of the $\mathrm{CM}$ to the responding $\mathrm{tPA}^{-/-}$microglia (100× magnification). Arrowheads, Membrane ruffles or pseudopods. Arrows, Phagocytic vacuoles.

cesses (Fig. 1a). With LPS stimulation, these cells began the process of activation in that their cell bodies and processes became slightly increased in volume (Fig. 1b).

In the presence of $\mathrm{CM}$ prepared from unstimulated wild-type or $\mathrm{PAA}^{-1-}$ neurons or microglia, the $\mathrm{tPA}^{-1-}$ microglia similarly exhibited very limited signs of activation (Fig. $1 c, g, k, o$ ). However, dramatic activation was observed in the presence of CM prepared from wild-type neurons subjected to simulated injury $(66.5 \%$ of the microglia were activated, as judged by altered morphology) [Fig. 1, $l$ (higher magnification) and $m$ (lower magnification)]. The 


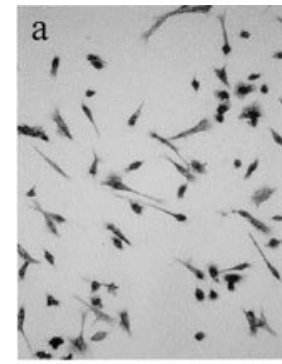

not treated

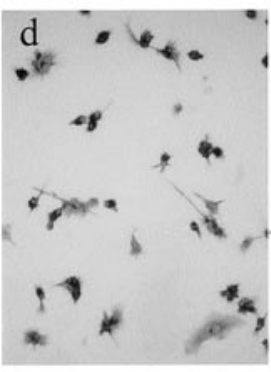

LPS

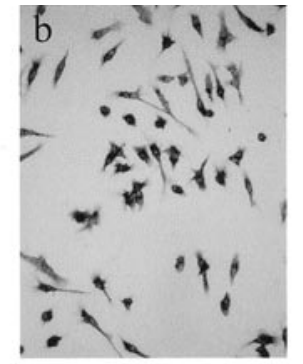

$5 \mathrm{ng} / \mathrm{ml} \mathrm{rtPA}$

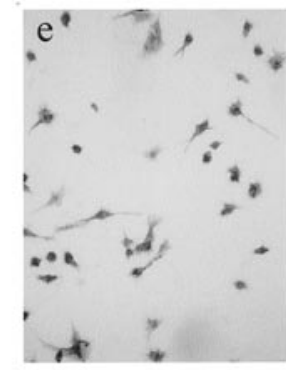

$5 \mathrm{ng} / \mathrm{ml} \mathrm{rtPA}$, LPS

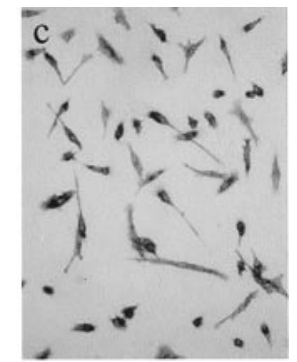

$1 \mu \mathrm{g} / \mathrm{ml} \mathrm{rtPA}$

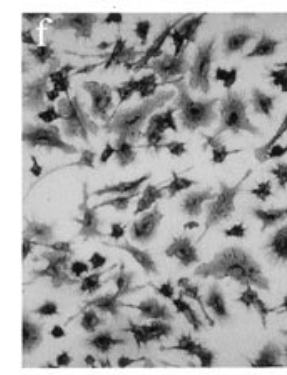

$500 \mathrm{ng} / \mathrm{ml} \mathrm{rtPA}$, LPS
Figure 2. tPA and LPS are required to activate $\mathrm{tPA}^{-1-}$ microglia. Microglia were cultured as indicated and then fixed and immunostained for F4/80 expression. $a$, Not treated; $b, 5 \mathrm{ng} / \mathrm{ml} \mathrm{tPA} ; c, 1 \mu \mathrm{g} / \mathrm{ml} \mathrm{tPA} ; d, 100$ $\mathrm{ng} / \mathrm{ml} \mathrm{LPS} ; e, 5 \mathrm{ng} / \mathrm{ml}$ tPA, LPS; $f, 500 \mathrm{ng} / \mathrm{ml}$ tPA, LPS. All panels are shown at $100 \times$ magnification.

cell membranes became ruffled (Fig. 1, arrowheads), and phagocytic vacuoles were observed in the cell bodies (Fig. 1, arrows). In contrast, CM prepared from injured $\mathrm{PPA}^{-/-}$neurons did not trigger activation $(6.8 \%)$ (Fig. 1d,e). CM prepared from LPSstimulated wild-type microglia similarly triggered activation (92.6\%) (Fig. 1p,q), whereas CM prepared from LPS-stimulated $\mathrm{tPA}^{-1-}$ microglia did not $(10.6 \%)$ (Fig. 1h,i). However, the $\mathrm{tPA}^{-1-}$-stimulated neuronal or microglial $\mathrm{CM}$ could be made functional with the addition of tPA (Fig. 1f,j). Finally, addition of an $\alpha$-tPA antibody to the stimulated wild-type neuronal or microglial CM impaired the ability of the CM to fully activate the responding $\mathrm{tPA}^{-/-}$microglia (Fig. 1n,r).

Together, these results show that wild-type but not $\mathrm{tPA}^{-1-}$ microglia and neurons, once primed or injured, release a factor(s) in the medium that activates $\mathrm{tPA}^{-1-}$ microglia. Because this factor can be replaced by purified tPA and can be blocked by anti-tPA antiserum, it is most likely tPA. The results demonstrate that both neurons and microglia are capable of mediating microglial activation through the release of tPA.

\section{tPA activates microglia in synergy with other stimuli}

Cultured microglia often adopt a slightly activated morphology [probably attributable to the culture preparation and conditions (Fig. 2a) (Nakajima et al., 1989)]. Stimulation of $\mathrm{tPA}^{-/-}$microglia with tPA does not induce significant morphological changes (Fig. 2, compare $a$ with $b$ and $c$ ). LPS treatment alone also induces a rapid (within $30 \mathrm{~min}$ ) but quite limited change in morphology in many cells (Fig. $2 d$ ). However, when the cells are treated with $500 \mathrm{ng} / \mathrm{ml}$ tPA plus LPS, the microglia become highly activated (Fig. $2 f$ ). This finding indicates that tPA alone does not suffice to activate microglia; instead, a second signal is required, which can be provided by LPS priming or by factors other than tPA released by stimulated microglia and neurons (Fig. 1).

Microglial activation as a function of tPA and LPS addition was quantified by Western blot analysis. The expression of the glycoprotein F4/80 is upregulated when cells of the monocyte-macrophage lineage are activated (Lawson et al., 1990). We detected an increase in F4/80 immunoreactivity after culturing $\mathrm{tPA}^{-/-}$ microglia with LPS and increasing concentrations of tPA. From baseline unstimulated levels, we found a 0.8 -fold increase with the lowest dose of tPA added $(5 \mathrm{ng} / \mathrm{ml})$, which increased to 2-fold with $50 \mathrm{ng} / \mathrm{ml}$ tPA and to 2.4-fold with $500 \mathrm{ng} / \mathrm{ml} \mathrm{tPA}$, indicating that the level of activation is dependent on the concentration of tPA (data not shown). Microglia secrete many other molecules during activation, including NO and TNF- $\alpha$ (Meda et al., 1995). The activated microglia were also found to secrete higher amounts of nitrites $(2.5 \pm 0.2 \mu \mathrm{M}$ at $500 \mathrm{ng} / \mathrm{ml} \mathrm{tPA}$, compared with $0.9 \mu \mathrm{M}$ from control cells), consistent with the immunochemical data shown in Figure 2 (data not shown).

\section{The finger domain of tPA mediates microglial activation}

tPA mediates microglial activation via a nonproteolytic mechanism, possibly through interactions with protein(s) on the microglial cell surface. We used tPA mutants lacking the finger $(\Delta \mathrm{F})$, growth factor $(\Delta \mathrm{GF})$, and kringle $(\Delta \mathrm{K} 1$ or $\Delta \mathrm{K} 2)$ domains to determine whether the absence of one or more of these domains abolished microglial activation. The $\Delta \mathrm{GF}, \Delta \mathrm{K} 1$, and $\Delta \mathrm{K} 2$ proteins activated $\mathrm{tPA}^{-1-}$ microglia as well as or better than full-length tPA, as judged by F4/80 upregulation (Fig. 3a), NO release (Fig. $3 b$ ), and morphological change (Fig. $3 c$ ). However, the $\Delta \mathrm{F}$ mutant did not elicit significant activation (see also Fig. $5 a$ ). The $\Delta \mathrm{F}$ mutant did not act as a dominant-negative or toxic factor, because wild-type levels of activation were observed when full-length tPA and $\Delta \mathrm{F}$ were used together in the activation assay (data not shown). Thus, the presence of the tPA finger domain is critical for mediating microglial activation.

\section{Microglial activation by the finger domain of tPA is receptor-mediated through annexin II}

One candidate for a microglial tPA receptor is annexin II (Hajjar et al., 1994). The $\mathrm{Ca}^{2+}$ - and phospholipid-dependent annexin II is a known receptor for tPA in endothelial cells (Hajjar et al., 1994). We found by RT-PCR and Western blot analysis that annexin II is expressed by microglial cells but not neurons (Fig. 4), suggesting that there could be a microglial-specific tPA signaling pathway.

To assess whether this pathway was functional, we preincubated $\mathrm{tPA}^{-/-}$microglia with a monoclonal $\alpha$-annexin II antibody for $1 \mathrm{hr}$ before tPA/LPS activation (Fig. $5 a$ ). Addition of the antibody alone (Fig. 5A, column 4 ) did not affect unstimulated cells (Fig. 5A, column 1). However, the antibody did block (Fig. $5 A$, column 5$)$ the activation normally elicited by tPA and LPS (Fig. 5A, column 2), as assessed by F4/80 upregulation. Similar results were observed by morphology (Fig. $5 b-d$ ) but not in the presence of an IgG1 isotype control (Fig. 5e). Finally, incubation with an antibody directed against LRP, which is a known receptor for tPA in liver cells (Bu et al., 1992), did not prevent microglial activation (Fig. 5f). These results suggest that the finger domain of tPA mediates microglial activation by signaling through the cell surface protein annexin II.

\section{DISCUSSION}

tPA mediates neuronal death and microglial activation during excitotoxic injury. We have reported previously that the proteolytic activation of plasmin by tPA is required for neurodegeneration to progress (Tsirka et al., 1997). The role of plasmin has been 

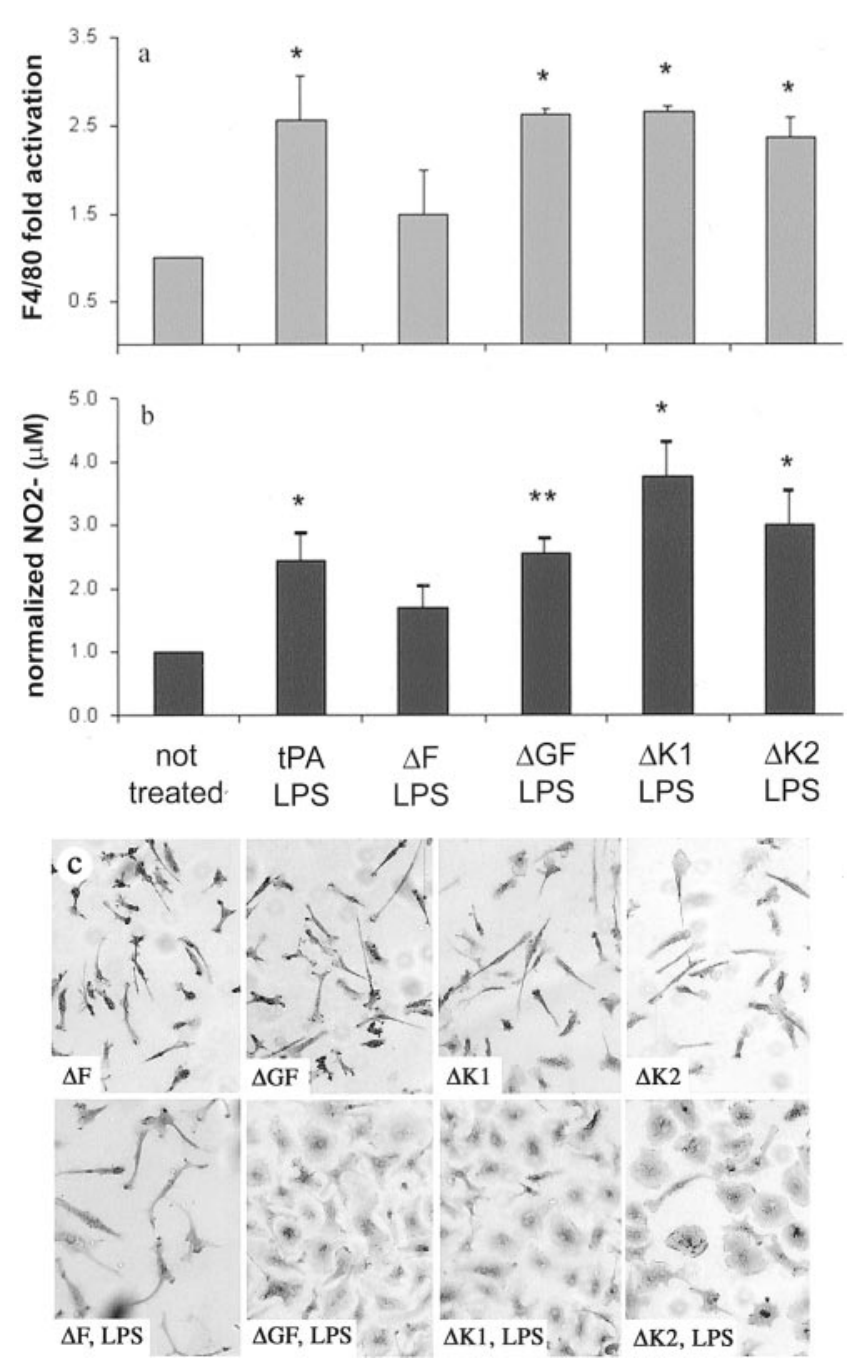

Figure 3. The finger domain of tPA mediates microglial activation. tPA $^{-1-}$ microglia were cultured with LPS in combination with full-length tPA ( $t P A L P S)$, tPA lacking the finger domain $(\triangle F L P S)$ or the growth factor domain $(\triangle G F L P S)$, or either of the kringle domains ( $\triangle K 1 L P S$ and $\Delta K 2$ LPS). a, Quantification of F4/80 expression by Western blot. $b$, Detection of NO release by its product, nitrite $\left(\mathrm{NO}_{2}{ }^{-}\right) .{ }^{*} p<0.01$; * $p<$ 0.05 . Data expressed are averages \pm SEM of triplicate experiments; all analyses were conducted using Student's $t$ test relative to the control cells that did not receive additions to the culture. $c, \mathrm{tPA}^{-1-}$ microglia were cultured on coverslips under the indicated conditions and then immunostained for F4/80 expression; panels are shown at $200 \times$ magnification.

proposed to involve subsequent degradation of ECM molecules, such as laminin (Chen and Strickland, 1997), resulting in loss of neuronal contact with the ECM, which may lead to apoptosis (Frisch and Ruoslahti, 1997; Frisch, 2000). However, the proteolytic activity of tPA is not necessary to activate microglia, suggesting an additional, cell-signaling function for tPA in the CNS (Rogove et al., 1999). Because tPA is secreted by both neurons and microglia, we addressed first whether either cell type released enough tPA into $\mathrm{CM}$ under conditions of stimulation to activate microglia. We found that stimulated $\mathrm{PPA}^{-/-}$neurons or microglia failed to induce activation in $\mathrm{PAA}^{-1-}$ microglia but that this result was reversed by addition of tPA into the cultures (Fig. 1). Finally, incubation with an antibody that sequesters the released tPA present in the stimulated wild-type CM partially (neuronal CM) to fully (microglial CM) inhibits the ability of the CM to mediate
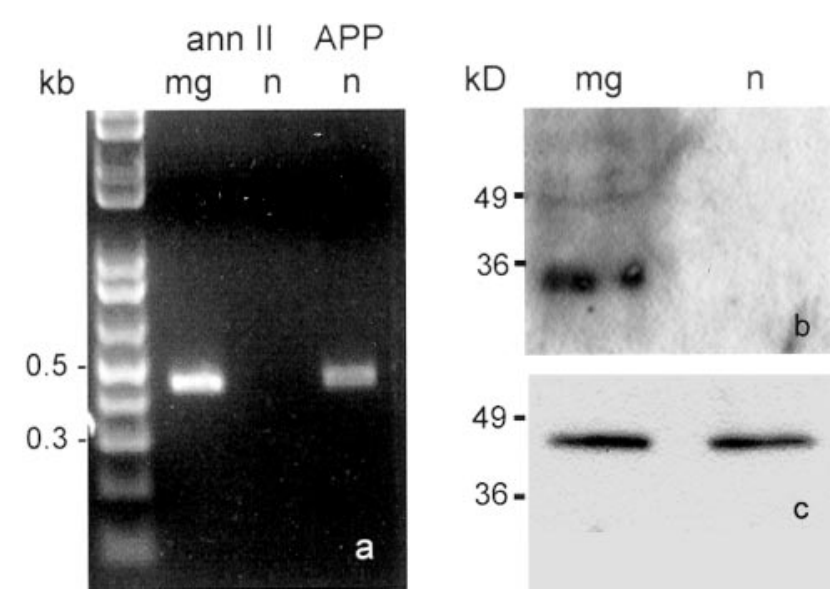

Figure 4. Primary microglia, but not neurons, express annexin II, a potential tPA receptor. $a$, RT-PCR results from microglia $(m g)$ or neurons $(n)$, amplified using either annexin II (ann II) or APP primers. The quality of the neuronal cDNA was established using the APP as a positive control (lane 4). $b$, Western blot confirming that primary microglia but not neurons express annexin II. The cell lysates used for the Western blot were also probed with the neuronal marker microtubule-associated protein 2 and the microglial marker F4/80 to confirm that the respective cell types had been highly enriched as intended and indicated (data not shown). $c$, An anti-actin antibody was used to ascertain equal protein loading for the lysates analyzed on the Western blot.

activation (Fig. 1; also see below for further discussion). These experiments confirm that one of the factors responsible for microglial activation after stimulation in our system is soluble tPA.

The finding that glutamate-injured neurons can release sufficient tPA to activate tPA ${ }^{-1-}$ microglia suggests a paracrine mechanism of microglial activation in vivo, in which the injured neurons would signal the immune cells of the CNS (i.e., the microglia) to scavenge damaging molecules secreted from the dying cells. In addition, we show that microglial activation can further stimulate release of microglial factors, such as tPA, that can in turn activate neighboring microglia in an autocrine or paracrine manner. This signal amplification ultimately leads to recruitment of microglia to the site of injury in the brain and can promote both a timely resolution of cellular injury and an overly sensitive inflammatory response. The data presented here support the role of tPA as a cytokine in this setting.

Our dose-response results indicate that there is a threshold for microglial reactivity to injury. It is widely accepted that microglia are the sensors of injury in the brain (Kreutzberg, 1996), and we propose that tPA acts as a microglial sensor molecule. Normally, the level of tPA released into the extracellular space is tightly regulated. tPA is stored in intracellular vesicles and is released only by $\mathrm{Ca}^{2+}$ influx during neuronal depolarization (Gualandris et al., 1996). Another level of control is afforded by the presence of several serine protease inhibitors in many regions of the brain [e.g., plasminogen activator inhibitors-1 and -2 and neuroserpin (Akiyama et al., 1995; Krueger et al., 1997)]. We and others have shown that tPA plays an important role in physiological processes such as neurite outgrowth (Seeds et al., 1999; Wu et al., 2000). This highly localized secretion of tPA, and hence localized activation of plasmin, is probably necessary for neurites to degrade ECM structures so that they can reach their targets. Therefore, neurons must be able to tolerate significant local increases in tPA activity surrounding them without sending out injury/death and inflammatory signals. To this end, we have shown that tPA alone 

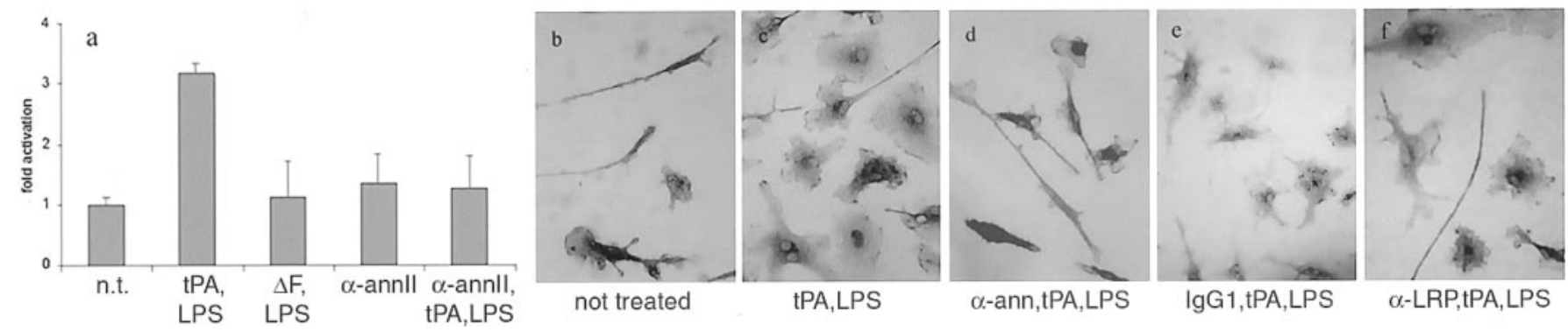

Figure 5. tPA-mediated microglial activation is blocked by $\alpha$-annexin II antibodies. $a$, Measurement of F4/80 expression by Western blot. tPA ${ }^{-/-}$ microglia were cultured with medium only [not treated (n.t.)]; LPS and $500 \mathrm{ng} / \mathrm{ml} \mathrm{tPA}(t P A, L P S) ; \mathrm{LPS}$ and $500 \mathrm{ng} / \mathrm{ml} \Delta \mathrm{F} \mathrm{mutant}(\Delta F, L P S) ; 1 \mu \mathrm{g} / \mathrm{ml}$ anti-annexin II ( $\alpha$-annII); or LPS, $1 \mu \mathrm{g} / \mathrm{ml}$ anti-annexin II, and $500 \mathrm{ng} / \mathrm{ml} \mathrm{tPA}(\alpha$-annII, tPA,LPS). Data from two independent experiments were pooled and plotted as fold activation over the control cells, which received no additions. Error bars indicate range of data points. $b-e$, tPA ${ }^{-1-}$ microglia were cultured alone or with $\alpha$-annexin II or $\alpha$-LRP antibodies for $1 \mathrm{hr}, 500 \mathrm{ng} / \mathrm{ml}$ tPA was added for another hour, and then LPS was added and the cells were incubated overnight. Activation was examined using F4/80 immunocytochemistry on fixed cells as described in Materials and Methods. The panels are shown at $400 \times$ magnification.

is not neurotoxic (Tsirka et al., 1996) (C.-J. Siao and S. E. Tsirka, unpublished observations). Like neurons, microglia must also be able to differentiate between high levels of tPA alone (which may be physiological) and high levels of tPA and some other factor, the combination of which is now an injury signal for microglia to become activated. In most of our experimental conditions, that other factor is bacterial LPS, whose presence is uncommon in the normal CNS. Physiological candidates would include proinflammatory molecules such as TNF- $\alpha$ and IL- $1 \beta$ that play important roles in activating microglia in culture (Meda et al., 1995). We believe that this cell-culture approach will help to define the identity of this other factor or factors. Indeed, our data using antibodies to block tPA binding to microglia and subsequent activation support this hypothesis (Fig. 1). Figure 1n (wild-type neuronal CM plus $\alpha$-tPA) shows more activated microglia than those in Figure $1 r$ (wild-type microglial CM plus $\alpha$-tPA). Because the same concentration of antibody was used and the same amount of tPA was released from each cell type (data not shown), an additional factor other than soluble tPA presumably is responsible for the advanced activation using neuronal CM. Recent data from our laboratory suggest that excitotoxic stimulation of hippocampal neurons results in the upregulation and secretion of active monocyte chemoattractant protein-1, which promotes microglial activation-migration (A. D. Rogove, J. Z. Sheehan, Y.-P. $\mathrm{Wu}$, Tsirka, unpublished observations).

The use of CM in a cell-culture setting is artificial, because of, among other reasons, the absence of cell types such as astrocytes, which can contribute to both amplification of tissue injury and containment of damage (Cui et al., 2001; Mandell et al., 2001). In addition, although LPS is widely used to prime cells of the monocyte/macrophage lineage for activation in vitro, this priming step would presumably be mediated in vivo by unknown endogenous factors. Finally, our findings show that microglia and neurons can release sufficient tPA in vitro, but not that they take up this role in vivo. All of these issues will be resolved by developing methods to address the questions using transgenic animal models, and these experiments are currently in progress.

To explore the mechanism of receptor-mediated microglial activation by tPA, we undertook a domain-deletion approach. Our results suggest that the finger domain of tPA plays a key role in activating microglia during excitotoxic injury. The slight activation of microglia in the cells treated with the $\Delta \mathrm{F}$ mutant and LPS is probably attributable to LPS priming. We would not predict that addition of the finger domain alone would completely reconstitute microglial activation; evidence suggests that the finger-growth factor domains interact with the catalytic domain (Novokhatny et al., 1991). Thus, the protease domain could also be involved (noncatalytically) in physically mediating activation. Recent data indicate that the catalytic domain may mediate tPA binding to human vascular smooth muscle cells (Werner et al., 1999). Mutants with catalytic domain deletions could be used to answer this question.

Annexin II, a $\mathrm{Ca}^{2+}$ - and phospholipid-binding protein, belongs to a family of proteins characterized by a highly conserved set of $\alpha$-helical repeats in the $\mathrm{C}$ terminus that mediate membrane binding (Mollenhauer, 1997). Annexin II is usually found as a heterotetramer consisting of two annexin II (p36) and two S100A10 (p11) subunits. A hexapeptide sequence in the $\mathrm{N}$ terminus of annexin II has been shown to bind to the finger domain of tPA and to increase tPA activity on endothelial cells (Hajjar et al., 1998). Because annexin II is a membrane-associated protein to which tPA and plasminogen presumably only dock, it is unclear how it may transduce inside the cells the activation signal resulting from the binding of extracellular tPA. Members of the annexin family are secreted to the cell surface via an unknown mechanism (Mollenhauer, 1997). Annexin II binds phosphatidylserine, so it could be cotranslocated across the membrane during early stages of apoptosis, although how and why this might occur during microglial activation is not at all clear.

Once inside the cell, the tPA/annexin II complex could signal in various ways. For example, the site at which tPA binds to annexin II is also where S100A10/p11 binds annexin II. One could envision a displacement and release of S100A10/p11 to function as an intracellular signal molecule. Alternatively, another as yet unidentified molecule associated with annexin II may mediate signaling cascades to activate microglia when tPA binds to annexin II. Annexin II is also a prominent intracellular signaling protein found in caveolas and lipid rafts, and it is phosphorylated by several kinases at key residues. Finally, annexin II is known to mediate interaction between cholesterol-rich membrane domains and the actin cytoskeleton (Filipenko and Waisman, 2001). This observation may underlie the changes in morphology during microglial activation. We are currently characterizing biochemically the interactions of the finger domain with annexin II and examining how this interaction mediates signal transduction.

tPA is used clinically as a thrombolytic agent during acute 
stroke. However, its neurotoxic effects in a mouse ischemia model suggest caution (Wang et al., 1998), because it can also activate microglia and lead to an exacerbation of neuronal death (Rogove and Tsirka, 1998; Rogove et al., 1999). Identification and further characterization of the tPA domain that activates microglia may aid in reducing inflammation and neurotoxicity. Mutating this binding region could lead to a clinically useful form of tPA that retains its thrombolytic properties yet does not trigger microglial activation.

A large body of research suggests that microglia can undertake either neurotoxic or neuroprotective roles in different disease or model settings (Dickson et al., 1993; Gehrmann et al., 1995; Benveniste, 1997; DiPatre and Gelman, 1997). It is highly likely that both roles exist. In addition to cleaning up debris from dead and dying cells, phagocytes are also required to contain damage so that other cells in the regions surrounding the injury are not damaged. However, overzealous reactive microglia can secrete excessive proinflammatory molecules, thus worsening the initial injury. Identification of annexin II as a microglial cell surface tPA receptor and characterization of the detailed interaction between the finger domain of tPA and annexin II would allow a potentially powerful method of interfering with microglial activation when such activation may be detrimental to the system as a whole.

\section{REFERENCES}

Akiyama H, Ikeda K, Kondo H, McGeer P, McGeer E (1995) Immunohistochemical study of type-1 plasminogen activator inhibitor (PAI-1) in brain. Soc Neurosci Abstr 21:741.

Benveniste E (1997) Role of macrophages/microglia in multiple sclerosis and experimental allergic encephalomyelitis. J Mol Med 75:165-173.

Bu G, Morton P, Schwartz A (1992) Identification and partial characterization by chemical cross-linking of a binding protein for tissue-type plasminogen activator (t-PA) on rat hepatoma cells. J Biol Chem 267:15595-15602.

Carmeliet P, Schoonjans L, Kieckens L, Ream B, Degen J, Bronson R, De Vos R, van den Oord J, Collen D, Mulligan R (1994) Physiological consequences of loss of plasminogen activator gene function in mice. Nature 368:419-424.

Chen Z-L, Strickland S (1997) Neuronal death in the hippocampus is promoted by plasmin-catalyzed degradation of laminin. Cell 91:917-925.

Cui W, Allen ND, Skynner M, Gusterson B, Clark AJ (2001) Inducible ablation of astrocytes shows that these cells are required for neuronal survival in the adult brain. Glia 34:272-282.

Dickson D, Lee S, Mattiace L, Yen S, Brosnan C (1993) Microglia and cytokines in neurological disease, with special reference to AIDS and Alzheimer's disease. Glia 7:75-83.

DiPatre P, Gelman B (1997) Microglial cell activation in aging and Alzheimer disease: partial linkage with neurofibrillary tangle burden in the hippocampus. J Neuropathol Exp Neurol 56:143-149.

Filipenko NR, Waisman DM (2001) The C terminus of annexin II mediates binding to F-actin. J Biol Chem 276:5310-5315.

Frisch SM (2000) Anoikis. Methods Enzymol 322:472-479.

Frisch SM, Ruoslahti E (1997) Integrins and anoikis. Curr Opin Cell Biol 9:701-706.

Gehrmann J, Banati R, Wiessner C, Hossmann K, Kreutzberg G (1995) Reactive microglia in cerebral ischaemia: an early mediator of tissue damage? Neuropathol Appl Neurobiol 21:277-289.

Gething M, Adler B, Boose J, Gerard R, Madison E, McGookey D, Meidell R, Roman L, Sambrook J (1988) Variants of human tissuetype plasminogen activator that lack specific structural domains of the heavy chain. EMBO J 7:2731-2740.

Giulian D (1999) Microglia and the immune pathology of Alzheimer disease. Am J Hum Genet 65:13-18.

Gonzalez-Scarano F, Baltuch G (1999) Microglia as mediators of inflammatory and degenerative diseases. Annu Rev Neurosci 22:219-240.

Gualandris A, Jones T, Strickland S, Tsirka S (1996) Membrane depolarization induces the $\mathrm{Ca}^{2+}$-dependent release of tissue plasminogen activator. J Neurosci 16:2220-2225.

Hajjar K, Jacovina A, Chacko J (1994) An endothelial cell receptor for plasminogen/tissue plasminogen activator. I. Identity with annexin II. J Biol Chem 269:21191-21197.
Hajjar KA, Mauri L, Jacovina AT, Zhong F, Mirza UA, Padovan JC, Chait BT (1998) Tissue plasminogen activator binding to the annexin II tail domain: direct modulation by homocysteine. J Biol Chem 273:9987-9993.

Kreutzberg G (1996) Microglia: a sensor for pathological events in the CNS. Trends Neurosci 19:312-318.

Krueger SR, Ghisu GP, Cinelli P, Gschwend TP, Osterwalder T, Wolfer DP, Sonderegger P (1997) Expression of neuroserpin, an inhibitor of tissue plasminogen activator, in the developing and adult nervous system of the mouse. J Neurosci 17:8984-8996.

Lawson L, Perry V, Dri P, Gordon S (1990) Heterogeneity in the distribution and morphology of microglia in the normal adult mouse brain. Neuroscience 39:151-170.

Mandell JW, Gocan NC, Vandenberg SR (2001) Mechanical trauma induces rapid astroglial activation of ERK/MAP kinase: evidence for a paracrine signal. Glia 34:283-295.

Meda L, Cassatella M, Szendrei G, Otvos Jr L, Baron P, Villaiba M, Ferrari D, Rossi F (1995) Activation of microglial cells by betaamyloid protein and interferon-gamma. Nature 374:647-650.

Mollenhauer J (1997) Annexins: what are they good for? Cell Mol Life Sci 53:506-507.

Nakajima K, Hamanoue M, Shimojo M, Takei N, Kohsaka S (1989) Characterization of microglia isolated from a primary culture of embryonic rat brain by a simplified method. Biomed Res 10 [Suppl 3]:411-423.

Novokhatny VV, Ingham KC, Medved LV (1991) Domain structure and domain-domain interactions of recombinant tissue plasminogen activator. J Biol Chem 266:12944-13002.

Olney J (1986) Inciting excitotoxic cytoside among central neurons. Adv Exp Med Biol 203:631-645.

Rabbani SA, Mazar AP, Bernier SM, Haq M, Bolivar I, Henkin J, Goltzman D (1992) Structural requirements for the growth factor activity of the amino-terminal domain of urokinase. J Biol Chem 267:14151-14156.

Rogove A, Tsirka S (1998) Neurotoxic responses by microglia elicited by excitotoxic injury in the mouse hippocampus. Curr Biol 8:19-25.

Rogove A, Siao C-J, Keyt B, Strickland S, Tsirka S (1999) Activation of microglia reveals a non-proteolytic cytokine function for tissue plasminogen activator in the central nervous system. J Cell Sci 112:4007-4016.

Russelakis-Carneiro M, Betmouni S, Perry VH (1999) Inflammatory response and retinal ganglion cell degeneration following intraocular injection of ME7. Neuropathol Appl Neurobiol 25:196-206.

Seeds N, Basham M, Haffke S (1999) Neuronal migration is retarded in mice lacking the tissue plasminogen activator gene. Proc Natl Acad Sci USA 96:14118-14123.

Si Q-S, Nakamura Y, Kataoka K (1997) Hypothermic suppression of microglial activation in culture: inhibition of cell proliferation and production of nitric oxide and superoxide. Neuroscience 81:223-229.

Stoll G, Jander S, Schroeter M (1998) Inflammation and glial responses in ischemic brain lesions. Prog Neurobiol 56:149-171.

Streit WJ, Walter SA, Pennell NA (1999) Reactive microgliosis. Prog Neurobiol 57:563-581.

Tsirka S, Gualandris A, Amaral D, Strickland S (1995) Excitotoxin induced neuronal degeneration and seizure are mediated by tissue-type plasminogen activator. Nature 377:340-344.

Tsirka S, Rogove A, Strickland S (1996) tPA and neuronal death. Nature 384:123-124.

Tsirka S, Rogove A, Bugge T, Degen J, Strickland S (1997) An extracellular proteolytic cascade promotes neuronal degeneration in the mouse hippocampus. J Neurosci 17:543-552.

van Zonneveld A-J, Veerman $\mathrm{H}$, MacDonald $\mathrm{M}$, van Mourik $\mathrm{J}$, Pannekoek H (1986) Structure and function of human tissue-type plasminogen activator (tPA). J Cell Biochem 32:169-178.

Wang Y, Tsirka S, Strickland S, Stieg P, Soriano S, Lipton S (1998) Tissue plasminogen activator (tPA) increases neuronal damage after focal cerebral ischemia in wild-type and tPA-deficient mice. Nat Med 4:228-232.

Werner F, Razzaq TM, Ellis V (1999) Tissue plasminogen activator binds to human vascular smooth muscle cells by a novel mechanism evidence for a reciprocal linkage between inhibition of catalytic activity and cellular binding. J Biol Chem 274:21555-21561.

Wu Y-P, Siao C-J, Lu W, Sung T-C, Frohman M, Milev P, Bugge T, Degen J, Levine J, Margolis R, Tsirka S (2000) The tPA/plasmin extracellular proteolytic system regulates seizure-induced hippocampal mossy fiber outgrowth through a proteoglycan substrate. J Cell Biol 148:1295-1304.

Yenari M, Giffard RG (2001) Ischemic vulnerability of primary murine microglial cultures. Neurosci Lett 298:5-8. 